\title{
VACINAS: PRIMÓRDIOS DE UMA PRÁTICA DA SAÚDE
}

\author{
VACCINES: THE BEGINNINGS OF A HEALTH PRACTICE
}

Ana Beatriz Silva Barbosa ${ }^{1}$, Anna D'Ávilla de Oliveira ${ }^{1}$, Halana Maria de Alencar Fonseca ${ }^{1}$, Ana Carla Isabelita de Lima $^{1}$, Rodrigo Augusto Cavalcante Fernandes ${ }^{1}$, Sérgio Everton Bessa Farias ${ }^{1}$, Waldineide Oliveira do Nascimento ${ }^{1}$, Rodrigo José Fernandes de Barros ${ }^{2}$, Jamile Rodrigues Cosme de Holanda ${ }^{2}$

${ }^{1}$ Acadêmicos da Faculdade Nova Esperança de Mossoró - FACENE/RN

${ }^{2}$ Professor da Faculdade Nova Esperança de Mossoró - FACENE/RN

Info

Recebido: 07/2020

Publicado: $11 / 2021$

DOI: 10.37951/2358-260X.2021v8i2.5909

ISSN: 2358-260X

\section{Palavras-Chave}

Promoção da saúde; Assistência integral a saúde; Atenção primária a saúde.

Keywords:

Health promotion; Comprehensive health care; Primary health care.

\section{Resumo}

Milhares de doenças infecciosas assolam a humanidade por muitos anos, desde o primeiro surto de peste que causou uma alta letalidade até os dias atuais, com doenças mais fortes e com alta disseminação. Assim com o decorrer dos anos foram surgindo as vacinas, inicialmente com o médico inglês Edward Jenner, criador da primeira vacina contra a varíola. Desta forma tal pesquisa busca fazer um levantamento sobre as criações das primeiras vacinas do mundo, normalmente desencadeadas após surtos de doenças que acometeram várias populações no passado da humanidade. Para tal foi realizada uma busca em acervos digitais que falassem sobre os primórdios da vacinação, sendo encontrado e utilizado mais livros que artigos. Para a busca utilizou-se as palavras chaves: "vacinação", "primórdios", "primeiras vacinas", "desenvolvimento" de formas associadas, utilizando o operador booleano "AND". E pode-se observar que após as anotações e experimentos de Jenner, muitos outros pesquisadores conseguiram desenvolver e aplicar testes com vacinas, hoje de forma bem mais controlada e detalhada. E que com a obrigatoriedade não se consegue vacinar a toda a população, visto as revoltas desencadeadas por ela. Assim, podemos concluir que a vacina, apesar de uma longa trajetória percorrida no Brasil e no mundo, alcançou a vacinação em massa produto fundamental à saúde e à qualidade de vida, além de demonstrar sua indispensabilidade para o homem como o segundo maior fator de redução da mortalidade.

\begin{abstract}
Thousands of infectious diseases plague humanity for many years, from the first outbreak of plague that caused a high lethality to the present day, with stronger diseases and with high spread. Thus, over the years, vaccines emerged, initially with the English physician Edward Jenner, creator of the first vaccine against smallpox. Thus, this research seeks to survey the creations of the world's first vaccines, usually triggered after disease outbreaks that affected various populations in the past of humanity. To this end, a search was carried out in digital collections that spoke about the beginnings of vaccination, finding and using more books than articles. For the search, the keywords were used: "vaccination", "beginnings", "first vaccines", "development" of associated forms, using the Boolean operator "AND". And it can be seen that after Jenner's notes and experiments, many other researchers were able to develop and apply vaccine tests, today in a much more controlled and detailed way. And that with the obligation it is not possible to vaccinate the entire population, given the revolts unleashed by it. Thus, we can conclude that the vaccine, despite a long trajectory covered in Brazil and in the world, has achieved mass vaccination, a fundamental product for health and quality of life, in addition to demonstrating its indispensability for man as the second largest reduction factor of mortality.
\end{abstract}


povos e povoados em todo o mundo. A peste anatômica, no período do famigerado Império Romano, foi um dos primeiros surtos registrados na história com alta letalidade, dizimando milhares de romanos, além de infectar Ásia menor, Egito, Grécia e Itália. Também é importante destacar a praga Justiniano e a peste negra, em cronologias distintas, mas igualmente letais e causadas pelo mesmo agente, a pulga do rato. A peste negra, muito mais avassaladora, embarcou em navios mercantilistas, os quais cruzavam os mares com mercadorias para todo o Oriente e Ocidente, para disseminar a pulga, que era um vetor fundamental para a propagação e, consequentemente, para a proporção caótica da peste negra no meio social, conforme descrito, por exemplo, na obra literária Decameron, de Giovanni Boccaccio [33].

Em meio a esse contexto infeccioso, as sociedades clamavam por soluções para essas mazelas, pois a cura não era somente questão de saúde coletiva, mas sim de sobrevivência, visto que viver nessa época era estar constantemente ameaçado por uma praga, mais um problema dentre tantos que permeava os indivíduos. Diante disso, a ciência, que naquele tempo era empírica, incessantemente buscava por remédios para a cura das infecções. Surge, assim, um processo de tratamento e prevenção que mais tarde se conheceria como vacina, mas que então não apresentava essa terminologia. Assim, até lá, as sociedades praticaram diversas ações para tentar encontrar a cura das doenças, desde rezas e magias, passando por líquidos milagrosos até a inalação de cascas de feridas, tudo isso com o objetivo de alcançar o remédio para os males do corpo [33].

O conhecimento empírico da Antiguidade Clássica forneceu a primeira evidência do que seria conhecido atualmente como vacina, como o historiador Tucídides, que observou que pessoas contaminadas com a praga de Atenas não tinham uma segunda infecção. Em virtude da dificuldade de comunicação do período em questão, essas evidências não eram disseminadas, o que dificultava a interação dos múltiplos conhecimentos existentes. Dessa forma, muitos anos se passaram para que outros registros fossem encontrados [31].

No Ocidente, berço da Medicina, outras evidências foram registradas, a exemplo da China, quando, no século XVI, eram trituradas cascas de feridas e postas para serem inaladas por doentes, técnica conhecida como atenuação de vírus ou variação. Mas o problema da comunicação ainda impedia que esses conhecimentos fossem difundidos, que intelectuais conversassem e trocassem ideias, e dessa forma cada sociedade tratava suas mazelas da forma que melhor lhe convinha. Vale ressaltar que justamente a dificuldade em questão fez essa técnica chegar a América do Norte por volta do século XVII, passando pela Europa até alcançar os Estados Unidos, resultando em um século de diferença para a disseminação de um conhecimento [17].

Nessa trajetória histórica, o médico inglês Edward Jenner, em 1796, em meio a um surto de varíola, fez um experimento rústico a partir da observação de que as ordenhadeiras, ao entrar em contato com a varíola bovina, ficavam protegidas da cepa humana. Então, contaminou duas pessoas, de diferentes formas, para ver a reação, e logo pôde fazer as primeiras afirmações, fato que marcou a criação da vacina. Acredita-se que seja por isso que o nome dado foi vacina, porque a varíola foi a primeira doença a ser combatida com essa nova invenção, que se utilizava dos bovinos [2].

Certo tempo depois, surge nesse cenário de busca por profilaxia o francês Louis Pasteur, o qual, no século XIX, começa a fazer estudos laboratoriais, para outros patógenos, seguindo a mesma lógica de Jenner, em uma forma mais científica, controlando o ambiente 
e garantido maior segurança em seus experimentos, afirmando assim o advento da vacina como um mecanismo efetivamente científico e baseado em evidências [8].

Esse grande avanço científico proporcionou o surgimento das primeiras campanhas de vacinação. A Inglaterra, financiadora de grande parte desse processo, em 1803 realizou a primeira campanha de vacinação gratuita, chefiada pelo então Jenner. Tal realidade foi seguida pelo Imperador Napoleão, o qual, em 1805, proporcionou a vacinação para todo o seu exército. Assim, foi questão de tempo para que a prática se difundisse para outros continentes [10].

Dessa forma, a vacina chega ao Brasil e uma das ações mais marcantes é a Revolta da Vacina no Rio de Janeiro, em 1904. Em meio a questões políticas e de saúde pública, a vacinação foi marcada por conturbação, revolta social e autoritarismo governamental, uma vez que o pouco conhecimento popular sobre tal advento dificultava essa ação de saúde coletiva, criando mitos e certo receio por parte dos mais diversos segmentos sociais com a nova prática profilática. Realidade essa superada, o Brasil se tornou um dos maiores promotores de imunização do mundo, conseguindo erradicar diversas doenças e levar qualidade de vida à população por meio da vacina, com um programa que garante o imunizante a todos [7].

Ao certo, a ciência evoluiu consideravelmente e propôs métodos eficazes e seguros para a criação das vacinas, as quais conhecemos atualmente. Erradicaramse doenças anteriormente nunca pensadas em serem exterminadas na sociedade, como a varíola, que perdurou anos para ser controlada, além da própria poliomielite, que criou uma geração de crianças deficientes. Enfim, a vacina proporcionou, além de melhorias na qualidade de vida dos indivíduos, maior expectativa de vida entre as sociedades [28].
Não se pode deixar de falar do contexto atual, a pandemia de um novo tipo de coronavírus, o Sarscov-2, o qual assola o mundo todo, dizimando a vida de milhares de pessoas, restringindo a circulação dos indivíduos e levando o caos especialmente aos mais vulneráveis. De fato, não se pode calcular o tamanho do prejuízo social que essa mazela trouxe, mas é de conhecimento amplo, baseado em toda uma trajetória histórica, que a vacinação é o método mais eficaz para acabar com essa pandemia, e mais uma vez a vacina mostra sua importância e sua necessidade para o desenvolvimento social [28].

Diante disso, o presente trabalho busca fazer um levantamento histórico sobre as epidemias e pandemias que ocorreram ao longo da história da humanidade, abordando o contexto vivenciado, as consequências humanitárias e as revoluções na saúde provocadas por elas, destacando a criação das primeiras vacinas do mundo e todas as outras que sucederam, não deixando de abordar as repercussões do coronavírus, em todo um contexto mundial, e dos desafios científicos para desenvolver a vacina contra o Sars-cov-2.

\section{METODOLOGIA}

Foi realizada uma revisão bibliográfica de artigos, livros e materiais de reportagem, disponibilizados em diversos acervos digitais. Considerando aqueles que discutissem, de maneira bem mais incisiva, sobre os primórdios da vacinação, a busca foi filtrada pela utilização das palavras-chave "vacinação", "primórdios", "primeiras vacinas", "desenvolvimento", de formas associadas, e do operador booleano "AND”.

Os documentos encontrados foram salvos, lidos os resumos e, após essa "triagem" para identificar se há alguma relação com o tema, os escolhidos foram utilizados para a construção deste. Ressalta-se que 
foram levadas em consideração todas as publicações em português, disponíveis na internet de forma integral através do Periódicos CAPES.

\section{REVISÃO DA LITERATURA E RESULTADOS}

A história da vacina começa no século XVIII, com o médico inglês Edward Jenner, nascido em Berkeley, na Inglaterra, em 17 de maio de 1749, que com apenas 13 anos de idade já ajudava um cirurgião em Bristol. Formou-se em Medicina em Londres, retornando à sua cidade natal em seguida para a realização de experimentos relacionados a varíola, que na época era a doença mais temida da humanidade, já que matava cerca de 400 mil pessoas por ano. Em 1789, Jenner começou a observar que pessoas que ordenhavam vacas não contraiam a varíola, desde que tivessem adquirido a forma animal da doença. $\mathrm{O}$ médico extraiu o pus da mão de uma ordenadora que havia contraído a varíola bovina e inoculou em um menino saudável chamado James Phipps, de oito anos de idade, em 4 de maio de 1796. Após Phipps contrair a doença de forma leve e logo em seguida se curar, no dia $1^{\circ}$ de julho, Jenner inoculou novamente no mesmo menino um líquido extraído de uma pústula de varíola humana e assim verificou que James não contraiu a doença, o que significava que estava imune a varíola [33].

A vacina então surgiu da observação de Jenner quanto ao fenômeno de proteção contra a varíola, que podia ser desenvolvida pelo contato de pessoas com uma doença que acometia bovinos, conhecida por cowpox (pústula de vaca). Em seu estudo reparou que pessoas que retiravam o leite de vacas não contraíam a varíola humana e acabou descobrindo que sua imunidade se devia à infecção não perigosa por cowpox. Então, a partir da pústula desenvolvida na vaca, obtinha um produto que passou a ser chamado de vacina (da vaca), que, ao ser inoculado no homem, fazia surgir no local das inoculações erupções bem parecidas com a da varíola. Dessas erupções, retirava-se o pus variólico, que era utilizado para outras inoculações, formando assim uma cadeia de imunização entre as pessoas, sendo o cow-pox considerado o primeiro agente imunizador [31].

Com isso, estava descoberta a primeira vacina com vírus atenuado e que em dois séculos conseguiria erradicar a doença. Phipps foi o decimo sétimo caso descrito no artigo de Jenner sobre vacinação, que se chamava "Um Inquérito sobre Causas e os Efeitos da Vacina da Varíola”. Jenner então relatou sua experiência à Royal Society, a Academia de Ciências do Reino Unido, porém suas provas foram consideradas insuficientes. No entanto o médico não parou, e seguiu realizando novas inoculações em outras crianças, inclusive em seu próprio filho. Em 1798, o seu trabalho enfim teve reconhecimento e foi publicado. Porém sua pesquisa era ridicularizada pelos que tomavam conhecimento, os quais a consideravam como um processo de infectar pessoas com material colhido de animais doentes. Contudo, os benefícios foram se tornando evidentes, deixando Edward Jenner famoso mundialmente por ter inventado a vacina. Em 1799 foi criado o primeiro instituto vacínico em Londres e no ano de 1800 a Marinha britânica começou a adotar a vacinação [31].

No Brasil, o uso da vacina contra a varíola foi declarado obrigatório para crianças em 1837 e para adultos em 1846, porém essa resolução não teve cumprimento eficaz, até porque a própria produção da vacina em escala industrial só começou no Rio de Janeiro em 1884. Sendo assim, em junho de 1904, o médico sanitarista Oswaldo Cruz motivou o governo a enviar ao Congresso um projeto de lei para reinstaurar a obrigatoriedade da vacinação em todo o território nacional. Para que assim houvesse efetividade nessa ação de vacinação foi imposto que apenas os indivíduos 
que comprovassem estarem vacinados conseguiriam contratos de trabalho, matrículas em escolas, certidões de casamento, autorização para viagem, dentre outras ações civis de um cidadão. Com isso, a lei foi aprovada em 31 de outubro e regulamentada em 9 de novembro, o que serviu de início para um marco histórico que ficou conhecido como Revolta da Vacina. Pelo fato de as pessoas não aceitarem tomar a injeção contra sua vontade, a população foi às ruas, para protestar, gerando não apenas esse confronto, mas diversos outros, que resultaram em inúmeras prisões, deportamentos, feridos e mortes [19].

Houve assim a desistência da vacinação obrigatória pelo governo de Rodrigues Alves, porém todos saíram perdendo, pois as pessoas foram castigadas pelo governo e também pela doença, já que a vacinação vinha crescendo e despencou, depois da tentativa de torná-la obrigatória. A ação do governo foi considerada desastrada e precipitada porque ocasionou a interrupção de um movimento ascendente de aceitação à vacina. Mais tarde, em 1908, quando o Rio de Janeiro foi atingido pela mais violenta epidemia de varíola da história, o povo correu para ser vacinado, em um marco histórico avesso à Revolta da Vacina, que foi a aceitação dela [19].

Outro marco histórico de grande relevância mundial foi a peste bubônica, também conhecida por peste negra, a qual era uma doença infecciosa causada pela bactéria Yersinia pestis. Tal doença ficou conhecida por devastar a Europa no final da Idade Média, havendo surtos nos séculos seguintes [2]. $\mathrm{O}$ bacteriologista francês de origem suíça, Alexandre Yersin, descobre, em 20 de junho de 1894, o bacilo da peste bubônica (Yersinia pestis) em Hong Kong, identificando também o rato como o vetor da epidemia. De regresso a Paris no ano seguinte desenvolveria com Albert Calmette e Émile Roux uma vacina e um soro contra a peste. Fundou diversas filiais do Instituto
Pasteur no Vietnã, vindo a se tornar diretor honorário da unidade de Paris em 1933. Para poder estudar Medicina na França, Yersin solicitou e obteve a nacionalidade francesa em 1888. Pouco depois partiu para a Indochina francesa, no Sudeste Asiático, como médico na companhia de Mensagería Marítima. Em 1894, Yersin foi enviado, a pedido do governo francês e do Instituto Pasteur, a Hong Kong, a fim de pesquisar a epidemia que ali grassava. Numa pequena cabana, próximo ao instituto, tendo ao seu lado o cientista japonês Kitasato Shibasaburo, fez sua grande descoberta do patógeno causador da peste. Demonstrou pela primeira vez que o mesmo bacilo estava presente tanto no rato quanto no ser humano, sublinhando assim a possível via de transmissão. Esta importante descoberta foi comunicada à Academia Francesa de Ciências no mesmo ano, por seu colega Emil Duclaux, num documento intitulado 'A Peste Bubônica em Hong-Kong' [8]. A partir de 1895 até 1897, Yersin aprofundou seus estudos sobre a peste bubônica. Em 1895 regressou ao Instituto Pasteur em Paris e com Émile Roux, Albert Calmette e Armand Borrel, preparou o primeiro soro anti-peste. No mesmo ano regressou a Indochina, onde instalou um pequeno laboratório em Nha Trang, com o fim de fabricar o soro. Em 1905 o laboratório local passou a ser um braço do Instituto Pasteur. Yersin testou o soro recebido de Paris em Cantão e Anoy em 1896, e em Bombaim, Índia, em 1897, com resultados desalentadores [8].

Considerada a mais trágica epidemia que a história registra, tendo produzido um morticínio sem paralelo, foi chamada de peste negra pelas manchas escuras que apareciam na pele dos enfermos. Como em outras epidemias, teve início na Ásia Central, espalhando-se por via terrestre e marítima em todas as direções. Em 1334 causou cinco milhões de mortes na Mongólia e no norte da China. Houve grande 
mortandade também na Mesopotâmia e na Síria, cujas estradas ficaram juncadas de cadáveres dos que fugiam das cidades. No Cairo os mortos eram atirados em valas comuns e em Alexandria os cadáveres ficaram insepultos. Calcula-se em 24 milhões o número de mortos nos países do Oriente [30]. Uma das maiores dificuldades era dar sepultura aos mortos: "Para dar sepultura à grande quantidade de corpos já não era suficiente a terra sagrada junto às igrejas; por isso passaram-se a edificar igrejas nos cemitérios; punhamse nessas igrejas, às centenas, os cadáveres que iam chegando; e eles eram empilhados como as mercadorias nos navios" (BOCCACCIO, 1979, p. 11-16). A epidemia se apresentou de duas maneiras. Nos primeiros dois meses manifestava-se com febre e expectoração sanguinolenta e os doentes morriam em três dias; decorrido esse tempo manifestou-se com febre contínua e edema nas axilas e nas virilhas e os doentes morriam em cinco dias. Era tão contagiosa que se propagava rapidamente de uma pessoa a outra; o pai não ia ver seu filho nem o filho a seu pai; a caridade desaparecera por completo. A peste negra foi a maior, mas não a última das epidemias. A doença perseverou sob a forma endêmica por muitos anos e outras epidemias menores, localizadas, foram registradas nos séculos seguintes [10].

Prática antiga, o embrião da técnica vacinal remonta ainda à China do século XVII, quando já se buscava uma maneira de combater a varíola, doença mortal à época, já que os tratamentos eram precários e não se conhecia muito a respeito do patógeno, um vírus. Assim, busca-se uma maneira de proteger a população, fazendo-a conhecer o inimigo invisível e inicialmente silencioso, ao se recolher material de pústulas de infectados para inoculação em indivíduos saudáveis, o que foi realizado pelo imperador K’ang. No entanto, tal pensamento inovador somente alcançou resultados mais disseminados quando o médico inglês Edward Jenner aprimorou a técnica de inoculação e provou que, ao se contrair varíola bovina, não havia possibilidade de se desenvolver varíola humana. A estratégia foi desenvolvida em laboratório pelo francês Louis Pasteur, que, ao prevenir a raiva, tornou claro o quão essencial a vacina seria como estratégia de saúde pública, mesmo alguns séculos depois [8].

O objetivo principal das vacinas seria, então, administrar uma apresentação enfraquecida do patógeno, de modo a desenvolver uma resposta imune sem provocar a sintomatologia da doença, para evitar que o indivíduo venha a contrai-la. Como em todos os estudos clínicos, o imunizante necessita passar por um rigoroso processo de pesquisa, desenvolvimento e controle de qualidade, objetivando oferecer sempre a maior eficácia com índices cada vez menores de efeitos colaterais. Nesse processo, a biotecnologia se mostra absolutamente indispensável, incorporando inovações que colaboram de maneira significativa com o processo. Primeiramente, é realizada uma pesquisa laboratorial minuciosa, que busca conhecer o agente etiológico de determinada doença, seus mecanismos fisiopatológicos e sua antigenicidade, para promover a intervenção adequada a cada caso. Os antígenos, considerados moléculas estranhas, que podem ser desde pequenas partes do micro-organismo até os próprios por inteiro, são preparados e purificados para posterior administração. A maneira de preparo varia de acordo com o tipo de vacina a ser desenvolvido, e, nesse caso, tem-se uma ampla gama de possibilidades [1].

Pode-se utilizar o micro-organismo atenuado ou modificado, que tem sua virulência drasticamente reduzida, principalmente pela promoção de infecções sequenciais em células in vitro, já que ocorrerão inúmeras mutações que resultarão em cepas menos virulentas, com patogenicidade muito inferior à do micro-organismo selvagem e intacto. Há também a 
vacina de patógeno inativado ou morto, que sofre essa inativação pelo uso de algumas substâncias químicas e necessita contar, em sua formulação, com os adjuvantes, agentes especiais que auxiliarão como coestimuladores da resposta imunológica a ser desenvolvida. Seguindo o mesmo princípio, tem-se a vacina de subunidade purificada, que também se apresenta com os adjuvantes mas não como o microorganismo completo, e sim como algumas partes retiradas dele e que são capazes de promover antigenicidade, os chamados epítopos. Atualmente, a indústria farmacêutica também tem apostado nas vacinas que utilizam como princípio o material genético, que pode ser DNA ou RNA, com relatos menos frequentes de efeitos colaterais graves [1].

Com a finalização do protótipo da composição, se iniciam os ensaios não-clínicos, que utilizam algumas espécies animais para a checagem de resultados, que serão posteriormente avaliados em humanos, já na fase dos ensaios clínicos. Este estágio é dividido em três subfases: I, que utiliza um grupo-intervenção pequeno, normalmente de 80 pessoas, e somente com voluntários saudáveis; II e III, que aumentam o número de voluntários, expandindo o perfil avaliado também. Por fim, os resultados obtidos são apresentados às agências reguladoras, como a Agência Nacional de Vigilância Sanitária (ANVISA), que, com uma equipe técnica multiprofissional, avaliará a relação risco-benefício e aprovará, ou não, a produção e comercialização do imunizante no país [16].

É importante ressaltar que todo o processo de estudo e produção de imunizantes passa por rigoroso controle de qualidade até que chegue à população, executado no cenário nacional pelo Instituto Nacional de Controle de Qualidade em Saúde (INCQS), uma subunidade da Fundação Oswaldo Cruz (Fiocruz) e também parte do Sistema Único de Saúde (SUS), criada em 1981 com o intuito de analisar e comprovar a eficácia de produtos biológicos e farmacêuticos, se utilizando para isso de evidências científicas em consenso com a comunidade internacional. Atua em estreito contato com a ANVISA, verificando de maneira técnica cada lote de imunizante, de modo a identificar qualquer intercorrência que venha a ser prejudicial para aplicação na população, garantindo a efetividade da biossegurança e atualizando protocolos e parâmetros legais para a tomada de decisões nesse quesito [25].

Considerando todas as fases e métodos de controle, é imprescindível enfatizar o papel das fábricas propriamente ditas, responsáveis pela preparação das fórmulas farmacêuticas que serão administradas no músculo deltoide. Internacionalmente, é impossível não mencionar o Instituto Serum, localizado na Índia e fundado inicialmente como uma empresa de cunho familiar, da casta dos Poonawalla, que eram criadores de equinos, e tiveram a ideia de fabricar produtos farmacêuticos a partir da extração de um soro, realizada em um de seus animais [13]. Fabricando imunizantes e medicamentos a preços reduzidos, graças ao baixo custo da mão-de-obra local, o instituto rapidamente se expandiu, concentrando um monopólio com a produção anual estimada em cerca de 1,5 bilhão de vacinas contra enfermidades das mais variadas, desde caxumba até poliomielite. Em âmbito nacional, deve-se destacar a atuação de duas interessantes organizações: o Instituto Butantan, de São Paulo, e a Fundação Oswaldo Cruz (Fiocruz), do Rio de Janeiro [16].

Com o desenvolvimento de pesquisas inovadoras, ambos os institutos investem na produção de imunobiológicos, aprimorando sua tecnologia para que este processo seja cada vez mais eficiente e rápido, e incorporando os resultados produtivos ao Programa Nacional de Imunização (PNI), parte integrante do SUS, o que amplia razoavelmente o acesso à imunização pela população, como também a outros produtos 
biofarmacêuticos, a citar os soros. Dessa forma, a colaboração para a saúde pública e o bem-estar social é inegável, com a contemplação de princípios e diretrizes do sistema, principalmente a equidade.

Atualmente o modo de produção vacinal persegue as etapas de um ensaio clínico, com fases préclínicas, executadas em laboratórios, geralmente, em seres animais, visando uma análise de dose e toxicidade nesta população. Os ensaios clínicos em seres humanos, são constituídos em quatro fases. O experimento da fase 1 pretende avaliar a garantia do produto; na fase 2, observa-se a garantia e a eficácia da dose e sua administração, assim como sua imunogenicidade; na fase 3, prioriza-se o desfecho e a segurança do produto, através de estudos clínicos equilibrados, randomizados, incluindo um número significativo de pessoas. Logo posteriormente, com a publicação científica dos dados, a vacina escolhida é submetida à análise pelas agências que administram para prosseguir com a produção e a distribuição. E finalmente, na fase 4, que é denominada de pós - licenciamento, considera-se os efeitos e eventos adversos após a finalidade da vacina em larga escala nos cidadãos. Porém, cada fase deste processo requer tempo, podendo durar cerca de meses a anos [27].

Portanto, observa-se que com o decorrer do tempo e de pesquisas a vacina é uma importante forma de imunização ativa (quando o próprio corpo produz os anticorpos) e baseia-se na introdução do agente causador da doença (atenuado ou inativado) ou substâncias que esses agentes produzem no corpo de uma pessoa de modo a estimular a produção de anticorpos e células de memória pelo sistema imunológico. Por causa da produção de anticorpos e células de memória, a vacina garante que, quando o agente causador da doença entre em contato com o corpo dessa pessoa, ela já esteja preparada para responder de maneira rápida, antes mesmo do surgimento dos sintomas da doença. A vacina é, portanto, uma importante forma de prevenção contra uma grande variedade de enfermidades [11].

Assim, a expectativa é que com o decorrer dos anos se tenha vacinas que possam ser administradas na população mundial de maneira ampla, demostrando ser a melhor solução para a prevenção de diversos óbitos. Obviamente, a vacina não pode substituir as políticas de prevenção e proteção de alguns grupos considerados mais vulneráveis a doença, devendo sempre haver associação entre tais medidas [27]. Não se pode desprezar a importância das pesquisas de segurança, das quais participam milhares de indivíduos, a fim de identificar reações adversas e cruciais contra a vacina, especialmente quando são utilizadas tecnologias de produção nunca antes manuseadas [11].

Algumas enfermidades sérias no que tange à saúde pública na contemporaneidade também são alvos de aprofundadas pesquisas sobre medidas vacinais, destacando-se a dengue e a contaminação por vírus perigosos, como o HIV e o H1N1, que ceifam inúmeras vidas e diminuem significativamente a qualidade de outras tantas.

Segundo dados da UNAIDS, existem 1,7 milhões de pessoas foram infectadas pelo $\mathrm{HIV}$ em 2019, 38 milhões pessoas vivem com HIV e 690 mil pessoas morreram de doenças relacionadas à AIDS [1]. Em 7 de fevereiro de 2005, a Índia deu início aos testes para a vacina preventiva contra o HIV, chamada tgAAC09 (vetor viral recombinante adeno-associado, rAAV). A tgAAC09 está sendo configurada sobre o subtipo C do HIV, que é o responsável pela maior parte das infecções no mundo, que consiste em uma cópia artificial de parte do material genético do HIV. A China publicou que começou os testes em seres da vacina em seres humanos, e que em 13 de março de 2005, um rapaz de 20 anos, foi o primeiro de grupo a receber a vacina, esta é composta por duas partes: uma contendo 
o DNA do HIV e outra carrega um vírus de varíola. A vacina que contém o DNA, auxilia os anticorpos e as células humanos a constituir a imunidade, e o vírus de varíola ajuda a fortalecer esta imunidade [2]. Após 10 anos, um protótipo da vacina, chega a fase 3 dos ensaios clínicos, que deve indicar se a vacina tem eficácia contra a transmissão do vírus. Essa última vacina está sendo desenvolvida pela Janssen, que se utiliza da mesma tecnologia que a farmacêutica usou em seu imunizante contra a covid-19, que se trata de um adenovírus modificado para transportar, até o interior das células dos infectados, o DNA das proteínas mais representativas, fazendo assim, que o organismo crie anticorpos contra ela. Trata-se de duas vacinas, uma sendo codificada por três proteínas e a outra por quatro, chamado de mosaico, por conter essa mistura, verificando que as duas criam anticorpos e superam os estudos de segurança. A última tentativa de se conseguir uma vacina contra o HIV teve seu fim em 2009, quando foi verificado que só tinha eficácia em 30\% das infecções [3]. Estima-se que a existência de uma vacina preventiva anti-HIV pode levar à erradicação da AIDS, a mesma terá um papel preventivo para as pessoas que não foram infectadas com o vírus, que nesse caso, ao entrarem em contato com o vírus, o organismos já teria anticorpos para combater a infecção. A vacina também teria um papel terapêutico para as pessoas já infectadas pelo vírus, tendo como objetivo a neutralidade do HIV logo após a reação do sistema imune [4].

Na década de 1930, já se ouvia falar em estudos sobre a vacina da dengue. Essa busca ganhou impulso, quando a dengue se dispersou pelas ilhas do Pacifico, ao longo da II Guerra Mundial. Após a guerra, Albert Sabin, desenvolveu uma vacina de vírus atenuado. A vacina foi desenvolvida com apenas dois sorotipos (DEN-1 e DEN-2), pois os demais (DEG-3 e DEN-4), ainda não eram conhecidos. A CYD-TDV (Dengvaxiaß), é vacina que atualmente está disponível, ela é uma formulação recombinante, quimérica, que contém os quatros sorotipos de DENV, que utiliza a cepa 17D, da vacina da febre amarela, como estrutura, onde são inseridos os segmentos geômicos de quatro tipos de DENV, que vão codificar as proteínas de prémembrana e envelope [6]. Essa é uma vacina atenuada, formulada pelos quatros sorotipos vivos do vírus, conseguido separadamente por tecnologia de DNA recombinante. Contendo aminoácidos essenciais, incluindo a fenilalanina, e aminoácidos não essenciais, entres eles, trealose di-hidratada, sorbitol, trometamol, sacarose, ureia e cloridato de arginina. Usa-se como diluente o cloreto de sódio e agua, para injeções. Não possui adjuvantes e conservantes. Essa vacina, é indicada para infecção causada pelos quatro sorotipos de dengue: DEN1, DEN2, DEN3 e DEN4. Quanto a sua a eficácia na prevenção da doença é de 65,5\%; na prevenção de dengue grave e hemorrágica é de 93\% e de internação é de mais de 80\%. Ela é administrada em 3 doses com intervalos de 6 meses. A vacina está liberada para crianças a partir de 9 anos de idade, até adultos até 45 anos, e tem sua recomendação para indivíduos previamente infectados por um dos vírus da dengue (soropositivos com ou sem história da doença). A vacina tem como contraindicações, gestantes, lactantes, pessoas imunodeprimidas, pessoas sem contato prévio com o vírus da dengue (soronegativos) e pessoas com alergias grave, anafilaxia, a algum dos componentes da vacina [7].

Mantendo a linha temporal de pandemias, no ano de 2009, em março, autoridades sanitárias no México, identificaram um surto causado pelo H1N1 uma nova cepa do vírus Influenza A, que o responsável por causar a pandemia de gripe espanhola que assombrou o mundo entre os anos de 1918 e 1920. A doença foi designada como "gripe A", "gripe mexicana" ou "gripe suína" (por conter ARN típico de vírus suínos). As primeiras vacinas começaram a ser 
desenvolvidas no segundo semestre do decorrente ano [8]. A vacina que é de vírus inativados, monovalente cepa H1N1 pandêmica 2009, tem sua eficácia em torno de $95 \%$. Trata-se de uma vacina trivalente de vírus vivos atenuados, adaptados ao frio, que contem cepas de vírus da influenza A H3N3, influenza A H1N1 e influenza B, que todo ano são alteradas conforme recomendações da OMS (Organização Mundial da Saúde). Após o $14^{\circ}$ e $21^{\circ}$ a aplicação da vacina, já se observa uma resposta máxima da produção de anticorpos [9].

No final do ano de 2019, surge na China, mais especificamente em Wuhan, um novo tipo de vírus, responsável por uma pneumonia atípica que inicialmente acomete alguns poucos trabalhadores do mercado de pescados local e rapidamente se espalha pela cidade. Sendo uma rota de passagem de inúmeros indivíduos, em especial a negócios, o município chinês vira palco da veloz transmissão para diversos outros locais, até que o patógeno, identificado como um novo tipo de coronavírus, atinge todas as partes do planeta, fazendo com que a Organização Mundial da Saúde (OMS) decrete se tratar de uma pandemia.

Com a transmissão se dando por vias respiratórias, através de gotículas de saliva contaminadas ou até por fômites, a principal tentativa de conter o problema é o isolamento social. Até então, as respostas às terapias medicamentosas eram das mais variadas, a letalidade aumentava exponencialmente e não se tinha outro meio de prevenir a contaminação que não fosse seguindo à risca o difícil processo de quarentena. A circulação de pessoas passa a ser duramente restringida por decretos, instituições de ensino, indústrias, escritórios e afins são fechados e apenas trabalhadores dos serviços essenciais, como segurança e saúde poderiam sair de suas casas para a labuta, e, ainda assim, devidamente protegidos com máscaras faciais. É possível imaginar e tentar mensurar o tamanho dos prejuízos socioeconômicos: desemprego, evasão escolar, uma pandemia de depressão e ansiedade e tantos outros exemplos. Assim, a comunidade científica mundial passa a depositar suas esperanças na profilaxia mais adequada para exterminar a doença e retomar o antigo normal: a vacina.

O maior equívoco sobre a vacina é achar que o trabalho começou no início da pandemia — na verdade, foi antes. Nas análises que a comunidade científica e de saúde fez após o surto do ebola, na África, surgiu um plano de como enfrentar o próximo grande problema. No final de uma lista de ameaças conhecidas estava a "doença X" — nome dado a uma nova infecção até então desconhecida, que mais tarde seria a famigerada infecção pelo vírus Sars-cov-2, a covid-19.

A peça central do plano era um tipo revolucionário de vacina chamado de "plug and play" (algo como conectar e ligar, em inglês). Ela possui duas características altamente desejáveis para enfrentar o desconhecido: é rápida e flexível. As vacinas convencionais — incluindo todo o programa de imunização infantil — usam uma forma morta ou enfraquecida do vírus original, ou injetam fragmentos dele no corpo, para que nosso sistema imunológico aprenda a combater a doença antes que ela seja uma ameaça. Mas esse tipo de vacina demora muito para ser desenvolvida. Em vez disso, os pesquisadores de Oxford construíram o ChAdOx1 - ou Chimpanzee Adenovirus Oxford One. Os cientistas pegaram um vírus do resfriado comum que infectou chimpanzés e o desenvolveram para se tornar o bloco de construção de uma vacina contra quase tudo.

Antes mesmo da pandemia de covid-19, 330 pessoas haviam recebido vacinas baseadas na ChAdOx1 para doenças que vão desde gripe ao vírus da zika, de câncer de próstata à chikungunya. As partículas que são capazes de estimular o corpo a produzir anticorpos (que atacam os vírus) são chamadas de antígenos. A 
ChAdOx1 é um tipo de antígeno que os pesquisadores modificam para produzir diferentes anticorpos. A ChAdOx1 é um tipo de antígeno que os pesquisadores modificam para produzir diferentes anticorpos. Ele funciona como um carteiro sofisticado e microscópico, promovendo a imunização adequada para evitar formas graves da infecção, e, consequentemente, mais mortes e hospitalizações.

Muito se tem discutido acerca da rapidez para aprovação de uma vacina, deixando de dar a devida credibilidade que o caso em questão merece, frente à necessidade que toda a população não apenas de um país, mas de todo o mundo tinha, afinal, as pesquisas foram realizadas muito antes do surgimento do covid, se iniciaram nas epidemias de SARS e MERS. Porém é de importante ressalva que devido a pandemia, que as pesquisas antes iniciadas adquiriram mais recursos e com isso, conseguiram se desenvolver rapidamente, devido aos financiamentos, apoio governamentais e de farmácias, havendo assim toda uma estrutura por trás do interesse de desenvolvimento da vacina, onde o mundo se mobilizou para a sua eficácia.

Há doenças para as quais até hoje não se tem a vacina. Sabendo que o imunizante é um produto caro, devido a demanda de pesquisas e a produção realizada por empresas farmacêuticas, estas por sua vez estão perdendo a intenção de produção, por perceber que se trata de um produto, do qual exige uma demanda financeira no qual não se tem o devido retorno.

$\mathrm{O}$ investimento deveria partir dos países que mais precisam da vacina, porém estes por sua vez não conseguem investir. Não havendo assim prioridade na pesquisa, mas é importante esclarecer que há sim tecnologia e a ciência necessária para desenvolver a vacina e combater assim a doença, mas falta recurso.

Quando se discute sobre essas doenças, vem em mente o HIV, o qual não teve vacina desenvolvida ainda, justamente por haver medicamentos caros que conseguem controlar o problema e de certa forma, já que as indústrias farmacêuticas visam o retorno lucrativo, que é o que se obtém com as medicações, não há assim interesse por parte deles de se investir em uma vacina que necessita, por sua vez, de mais investimento e que vai render menos lucro comparado ao obtido nas medicações de controle.

\section{CONCLUSÃO}

A busca pela saúde e qualidade de vida sempre marcaram as civilizações. Durante muitos anos as pessoas morriam sem ao menos conseguir estabelecer a causa mortis. Outras vezes, embora a causa fosse conhecida, atingindo inclusive muitos indivíduos, não havia meios para evitar a doença. Neste contexto, a descoberta da vacina, uma das maiores conquistas da humanidade, representa um dos principais avanços para a redução da mortalidade e melhoria da qualidade de vida, visto que a imunização permitiu o controle e erradicação de doenças infectocontagiosas que provocavam grande mortalidade.

É sabido que história da vacina se iniciou no século XVIII, quando o médico inglês Edward Jenner, através dos seus estudos, criou e utilizou a vacina para prevenir a contaminação por varíola, uma doença viral e extremamente grave. A varíola foi a primeira doença infecciosa que foi erradicada de maneira definitiva por meio da vacinação.

Uma longa trajetória foi percorrida no Brasil e no mundo, até que a vacinação em massa chegasse ao patamar atual, seja pelo temor inicial da própria vacina, pelo medo de adquirir características do animal ou de contrair a doença em sua forma mais grave, dentre outros, que dificultaram a disseminação da cultura da vacina, chegando a causar revolta na população.

É fundamental ratificar a importância da vacina como produto fundamental à saúde e à qualidade de vida, além de demonstrar sua indispensabilidade para o 
homem como o segundo maior fator de redução da mortalidade. A vacina é o maior avanço da imunologia e, atualmente, a técnica médica mais efetiva no controle e prevenção das doenças infectocontagiosas e a mais significativa para a saúde pública. Trata-se de um método totalmente seguro e eficaz em todas as fases da vida. As vacinas são responsáveis pela diminuição considerável e até erradicação de doenças graves, capazes de causar a morte prematura de pessoas ou sequelas que as acompanhariam para o resto da vida. Sem elas as taxas de mortalidade infantil seriam mais elevadas e a expectativa de vida seria menor.

É importante salientar que a vacinação é um ato de responsabilidade coletiva. Ao se imunizar contra uma doença o indivíduo não protege apenas a própria saúde, mas também a de todos ao seu redor. Os benefícios diretos e indiretos gerados com ações de imunizações são inequívocos e surpreendentes: inúmeras evidências demonstram seu potencial de redução da mortalidade, melhoria das condições de saúde e bem-estar das comunidades, além de representar economia para a sociedade, tanto através de redução de custos com consultas, tratamentos e internações hospitalares decorrentes das doenças como de menor absenteísmo escolar e de trabalho. Dessa forma, o grande desafio que se apresenta a todos nós é o de apoiar, através de educação, informação e conscientização, ações que promovam o alcance das imunizações a todas as comunidades.

Acreditamos que a importância das vacinas para a sociedade ficou ainda mais evidente com a pandemia da Covid-19. A importância da vacina contra a COVID-19 é prevenir casos graves da doença e evitar hospitalizações e mortes pelo novo coronavírus. A vacina é uma forma segura e inteligente de produzir uma resposta imunológica, ou seja, proteção no nosso organismo sem causar doença. As vacinas são projetadas para estimular memória imunológica. Ou seja, nosso sistema imunológico é induzido pela vacinação a lembrar do contato com aquele microrganismo (ou parte dele) contido na vacina, deixando-nos protegido contra uma doença por meses, anos, décadas ou mesmo toda a vida. E a tão esperada vacina contra a COVID 19 chegou como uma luz no fim do túnel, provando que vacinas salvam vidas. São necessárias elevadas coberturas vacinais para bloquear a cadeia de transmissão do vírus e é importante que cada um faça a sua parte. É importante lembrar sempre que a vacinação é uma ação de saúde coletiva. Além de estarmos nos protegendo individualmente, estamos protegendo também por tabela aqueles que estão ao nosso redor e que, por algum motivo, tenham uma contraindicação às vacinas em uso.

Diante do exposto, a vacina representou e ainda representa um grande avanço para a melhoria da saúde e qualidade de vida humana. Sua história é escrita continuamente, pois, a cada nova descoberta, surge a possibilidade de o homem obter melhores condições de vida.

\section{REFERÊNCIAS BIBLIOGRÁFICAS}

[1] ABBAS et al. Imunologia Celular e Molecular. 9. ed. Rio de Janeiro: Elsevier, 2019. p. 946-949.

[2] ATLAS DA SAÚDE. História das vacinas. Disponível em: https://www.atlasdasaude.pt/publico/content/hi storia-das-vacinas. Acesso em: 8 mai. 2021.

[3] ATLAS HISTÓRICO DO BRASIL - FGV. Revolta da Vacina. Disponível em: https://atlas.fgv.br/verbetes/revolta-da-vacina. Acesso em: 8 mai. 2021.

[4] BERTOLLI FILHO, Claudio. História da vacina e da vacinação em São Paulo: séculos XVIII e XIX. Cadernos de História da Ciência, v. 4, n. 1, p. 85-111, 2008. 
[5] BOCCACCIO, Giovanni. Decameron. Bur, p.1116, 2013.

[6] BUTANTAN. O Instituto. Disponível em: https://butantan.gov.br/institucional/o-instituto. Acesso em: 8 mai. 2021.

[7] CASTRO, Celso; GAGLIARDI, Juliana. A revolta da Escola Militar da Praia Vermelha (1904). Militares e Política, n. 5, 2009.

[8] CENTRO CULTURAL DO MINISTÉRIO DA SAÚDE. Louis Pasteur. Disponível em: http://www.ccms.saude.gov.br/revolta/personas /pasteur.html. Acesso em: 8 mai. 2021.

[9] CENTRO DE ESTUDOS ESTRATÉGICOS FIOCRUZ. Combate à epidemia de H1N1: um histórico de sucesso. Disponível em: https://cee.fiocruz.br/?q=node/1314. Acesso em: 10 mai. 2021

[10] CENTROCOR RIO CLARO. Conhecendo um pouco da história das vacinas. Disponível em: http://www.centrocorrioclaro.com.br/conhecen do-historia-vacinas/. Acesso em: 8 mai. 2021.

[11] CUETO, Marcos. Covid-19 e a corrida pela vacina. História, Ciências, SaúdeManguinhos, v. 27, n. 3, p. 715-717, 2020.

[12] EL PAÍS. Uma vacina contra o HIV chega à última fase de testes pela primeira vez em mais de 10 anos. Disponível em: https://brasil.elpais.com/internacional/2020-1201/uma-vacina-contra-o-hiv-chega-a-ultima-fasede-testes-pela-primeira-vez-em-mais-de-10anos.html. Acesso em: 10 mai. 2021.

[13] EXAME. Nos bastidores da maior fábrica de vacinas do mundo, o Instituto Serum, na Índia. Disponível em: https:// exame.com/ciencia/nos-bastidores-damaior-fabrica-de-vacinas-do-mundo-o-institutoserum-na-india/. Acesso em: 7 mai. 2021.

[14] FERNANDES, Tania. Vacina antivariólica: seu primeiro século no Brasil (da vacina jenneriana à animal). História, Ciências, SaúdeManguinhos, v. 6, n. 1, p. 29-51, 1999.

[15] FEIJÓ, Ricardo Becker; SÁFADI, Marco Aurélio P. Imunizações: três séculos de uma história de sucessos e constantes desafios. Jornal de Pediatria, v. 82, n. 3, p. s1-s3, 2006.
[16] FUNDAÇÃO EDSON QUEIROZ. Saiba como é feita uma vacina e como ela funciona no organismo. Disponível em: https://www.unifor.br/-/saiba-como-e-feitauma-vacina-e-como-ela-funciona-no-organismo. Acesso em: 7 mai. 2021.

[17] FUNDAÇÃO OSWALDO CRUZ. Vacinas: as origens, a importância e os novos debates sobre seu uso. Disponível em: https://www.bio.fiocruz.br/index.php/br/notici as/1263-vacinas-as-origens-a-importancia-e-osnovos-debates-sobre-seu-

uso?showall=1\&limitstart. Acesso em: 8 mai. 2021.

[18] FUNDAÇÃO OSWALDO CRUZ. Conheça a história das vacinas. Disponível em: https://www.bio.fiocruz.br/index.php/br/notici as/1738-conheca-a-historia-das-vacinas. Acesso em: 9 mai. 2021.

[19] FUNDAÇÃO OSWALDO CRUZ. A Revolta da Vacina. Disponível em: https://portal.fiocruz.br/noticia/revolta-davacina-2. Acesso em: 9 mai. 2021.

[20] FUNDAÇÃO OSWALDO CRUZ. A Fundação: História. Disponível em: https://portal.fiocruz.br/historia. Acesso em: 8 mai. 2021.

[21] FUNDAÇÃO OSWALDO CRUZ. Vacinas virais. Disponível em: https://www.bio.fiocruz.br/index.php/br/pergu ntas-frequentes/perguntas-frequentes-vacinasmenu-topo/131-plataformas/1574-vacinasvirais \#: :text $=\mathrm{A} \% 20 \mathrm{vacina} \% 20$ atenuada $\% 20 \% \mathrm{C}$ $3 \%$ A $9 \% 20$ aquela,forma $\% 20$ selvagem $\% 20$ causan do $\% 20 \mathrm{a} \% 20$ doen $\%$ C3\%A7a. Acesso em: 7 mai. 2021.

[22] GRUPO DE INCENTIVO À VIDA. Vacinas Anti-HIV/Aids. Disponível em: http://www.giv.org.br/Projetos/Vacinas-AntiHIV-AIDS/index.html. Acesso em: 10 mai. 2021.

[23] GRUPO DE INCENTIVO À VIDA. ÍNDIA E CHINA INICIAM TESTES DE VACINAS CONTRA HIV. Disponível em: http://www.giv.org.br/projetos/vacinas/cdrom/ boletins/boletim13/14_breves.htm. Acesso em: 10 mai. 2021.

[24] HISTÓRIA, CIÊNCIAS, SAÚDEMANGUINHOS. 1894: Alexandre Yersin 
descobre o bacilo da peste bubônica. Disponível em:

http:/ / www.revistahcsm.coc.fiocruz.br/1894alexandre-yersin-descobre-o-bacilo-da-pestebubonica/. Acesso em: 9 mai. 2021.

[25] INSTITUTO NACIONAL DE CONTROLE DE QUALIDADE EM SAÚDE. Papel do INCQS no controle da qualidade das vacinas: diretor do INCQS concede entrevista ao Canal Saúde. Disponível em: https://www.incqs.fiocruz.br/index.php?option =com_content\&view=article\&id=2112:papel-doincqs-no-controle-da-qualidade-das-vacinasdiretor-do-incqs-concede-entrevista-ao-canalsaude $\&$ catid $=42 \&$ Itemid $=132$. Acesso em: 8 mai. 2021.

[26] INSTITUTO NACIONAL DE CONTROLE DE QUALIDADE EM SAÚDE. Apresentação. Disponível em: https://www.incqs.fiocruz.br/index.php?option $=$ com_content\&view $=$ article\&id $=61 \&$ Itemid $=57$ . Acesso em: 8 mai. 2021.

[27] LIMA, Eduardo Jorge da Fonseca; ALMEIDA, Amalia Mapurunga; KFOURI, Renato de Ávila. Vacinas para COVID-19-o estado da arte. Revista Brasileira de Saúde Materno Infantil, v. 21, p. 13-19, 2021.

[28] MORAES, Luana Raposo de Melo et al., Eventos adversos de vacinas e as consequências da não vacinação: uma análise crítica. Revista de Saúde Pública, v. 52, p. 40, 2018.
[29] PEDIATRIA SOCIEDADE BRASILEIRA DE IA. Vacinas contra dengue: atualização. Disponível em: https://www.sbp.com.br/fileadmin/user_upload /Imunizacoes_-_Vacinas_contra_dengue__atualizacao_.pdf. Acesso em: 10 mai. 2021.

[30] REZENDE, JM. À sombra do plátano: crônicas de história da medicina [online]. São Paulo: Editora Unifesp, 2009. As grandes epidemias da história. p. 73-82.

[31] RUSSO, Carlos. Peste de Atenas: primeira emergência sanitária narrada é um retrato do presente. UOL. São Paulo, 2020. 1 p. Disponível em:

https://dialogosdosul.operamundi.uol.com.br/cu ltura/64467/peste-de-atenas-primeiraemergencia-sanitaria-narrada-e-um-retrato-dopresente. Acesso em: 8 mai. 2021.

[32] SILVA, Luiz Jacintho da. Vacina contra a dengue: uma luz no final do túnel? BEPA, Bol. epidemiol. paul. (Online), São Paulo, v. 9, n. spe, maio 2012. Disponível em http://periodicos.ses.sp.bvs.br/scielo.php?script =sci_arttext\&pid=S1806-

42722012001300002\&lng $=$ pt\&nrm $=$ iso. Acesso em: 10 mai. 2021.

[33] ZARAMELA, Luciana. As piores pandemias da história. Canaltech. 2020. 1 p. Disponível em: https://canaltech.com.br/saude/as-piorespandemias-da-historia-164788/. Acesso em: 8 mai. 2021. 